\title{
Dietary sodium and potassium intake in relation to non-alcoholic fatty liver disease
}

\author{
Yuni Choi $^{1}$, Jung Eun Lee ${ }^{2 *}$, Yoosoo Chang ${ }^{1,3,4}$, Mi Kyung Kim5, Eunju Sung ${ }^{6}$, Hocheol Shin ${ }^{6}$ and \\ Seungho Ryu ${ }^{1,3,4 *}$ \\ ${ }^{1}$ Center for Cohort Studies, Total Healthcare Center, Kangbuk Samsung Hospital, Sungkyunkwan University School of \\ Medicine, Seoul, 04514, Republic of Korea \\ ${ }^{2}$ Department of Food and Nutrition, Seoul National University, Seoul, 08826, Republic of Korea \\ ${ }^{3}$ Department of Occupational and Environmental Medicine, Kangbuk Samsung Hospital, Sungkyunkwan University School of \\ Medicine, Seoul, 03181, Republic of Korea \\ ${ }^{4}$ Department of Clinical Research Design E Evaluation, SAIHST, Sungkyunkwan University, Seoul, O6351, Republic of Korea \\ ${ }^{5}$ Department of Preventive Medicine, College of Medicine, Hanyang University, Seoul, 04763, Republic of Korea \\ ${ }^{6}$ Department of Family Medicine, Kangbuk Samsung Hospital, Sungkyunkwan University, School of Medicine, Seoul, o3181, \\ Republic of Korea
}

(Submitted 20 March 2016 - Final revision received 12 August 2016 - Accepted 20 August 2016 - First published online 11 October 2016$)$

\section{Abstract}

A few epidemiological data are available assessing the associations of intakes of sodium (Na) and potassium (K) with non-alcoholic fatty liver disease (NAFLD). We aimed to examine the associations of dietary intake of $\mathrm{Na}$ and $\mathrm{K}$ with the prevalence of ultrasound-diagnosed NAFLD. We performed a cross-sectional study of 100177 participants (46596 men and 53581 women) who underwent a health screening examination and completed a FFQ at the Kangbuk Samsung Hospital Total Healthcare Centers, South Korea, between 2011 and 2013. NAFLD was defined by ultrasonographic detection of fatty liver in the absence of excessive alcohol intake or other known causes of liver disease. The proportion of NAFLD was $35.6 \%$ for men and $9.8 \%$ for women. Increasing prevalence of NAFLD was observed with increasing Na intake. The multivariableadjusted prevalence ratios (PR) of NAFLD comparing the highest with the lowest quintile of energy-adjusted Na intake were $1 \cdot 25$ (95\% CI $1 \cdot 18$, $\left.1.32 ; P_{\text {trend }}<0.001\right)$ in men and $1.32\left(95 \%\right.$ CI $\left.1.18,1.47 ; P_{\text {trend }}<0.001\right)$ in women. However, when we additionally adjusted for body fat percentage, the association became attenuated; the corresponding PR of NAFLD were 1.15 (95\% CI 1.09, 1.21) in men and 1.06 (95\% CI 0.95, 1.17) in women. No inverse association was observed for energy-adjusted $\mathrm{K}$ intake. Our findings suggest that higher Na intake is associated with a greater prevalence of NAFLD in young and middle-aged asymptomatic adults, which might be partly mediated by adiposity.

\section{Key words: Sodium: Potassium: Diet: Non-alcoholic fatty liver disease}

Non-alcoholic fatty liver disease (NAFLD) has become the most common chronic liver disease ${ }^{(1)}$. NAFLD represents excessive fat accumulation, mainly in the form of triglyceride (TG), within hepatocytes and includes a broad spectrum of liver diseases from simple steatosis progressing through non-alcoholic steatohepatitis and cirrhosis ${ }^{(2)}$. Several metabolic disorders including obesity, insulin resistance, hypertension and dyslipidaemia are key pathogenic factors in the development of NAFLD ${ }^{(3)}$.

The current World Health Organization ${ }^{(4,5)}$ guidelines based on a systematic review of epidemiological literature recommend that adults eat $<2000 \mathrm{mg} / \mathrm{d}$ of sodium $(\mathrm{Na})$ but at least $3510 \mathrm{mg} / \mathrm{d}$ of potassium (K) to improve health consensuses related to blood pressure (BP) and cardiovascular events. Although the association between $\mathrm{Na}$ intake and insulin resistance has not been as well studied as the association for BP, several evidences have suggested the potential link between $\mathrm{Na}$ intake and insulin sensitivity. A positive relationship between dietary $\mathrm{Na}$ intake and insulin resistance has been observed in animal studies ${ }^{(6,7)}$, and high $\mathrm{Na}$ intake has been shown to induce insulin-related adipose tissue accumulation in rats ${ }^{(8)}$. In human studies, there is evidence that high $\mathrm{Na}$ intake has an adverse effect on insulin resistance ${ }^{(9)}$, and that it is independently associated with an increased risk of type 2 diabetes after adjusting for risk factors including physical activity, obesity and hypertension $^{(10)}$. In addition, epidemiological studies have shown a positive association between $\mathrm{Na}$ intake and body size and fatness, independent of energy or sugary beverage intake $^{(11-13)}$. For K intake, some epidemiological studies found an increased risk of diabetes with low $\mathrm{K}$ intake ${ }^{(14,15)}$, while others have not shown such an association ${ }^{(10,16)}$. K intake was

Abbreviations: BF\%, body fat percentage; BP, blood pressure; FLI, fatty liver index; NAFLD, non-alcoholic fatty liver disease; PR, prevalence ratio.

* Corresponding authors: J. E. Lee, fax +82 2884 0305, email jungelee@snu.ac.kr; S. Ryu, fax +82 2 757 0436, email sh703.yoo@gmail.com 
inversely associated with the metabolic syndrome and insulin resistance in some observational studies ${ }^{(17,18)}$.

Given the evidence of links between inadequate levels of $\mathrm{Na}$ and $\mathrm{K}$ intake and metabolic disorders, it could be hypothesised that metabolic milieu in individuals who consume high $\mathrm{Na}$ and/ or low K levels may trigger several pathophysiological processes favouring the development of NAFLD. Thus, we evaluated the associations between dietary intake of $\mathrm{Na}, \mathrm{K}$, and $\mathrm{Na}: \mathrm{K}$ ratio and prevalence of ultrasound-diagnosed NAFLD in a large population-based screening study.

\section{Methods}

\section{Study population}

The Kangbuk Samsung Health Study is a cohort study of Korean men and women who underwent comprehensive annual or biennial examinations at two Kangbuk Samsung Hospital Total Healthcare Centers in Seoul or Suwon, South Korea ${ }^{(19,20)}$. The study population included 206996 participants who completed a FFQ and underwent a comprehensive health check-up between March 2011 and April 2013. After participants had completed the self-administered questionnaires, clinical examinations including abdominal ultrasound were performed.

For the current analysis, we excluded a total of 106819 participants who met exclusion criteria, which included the following: missing data on abdominal ultrasound or age ( $n$ 121); a history of liver disease or medication use for liver disease ( $n$ 22363); the presence of positive serological markers for hepatitis $\mathrm{B}$ or $\mathrm{C}$ virus ( $n$ 7621); use of medications associated with NAFLD within the past year, such as valproate, amiodarone, methotrexate, tamoxifen or corticosteroids ( $n$ 2969) ${ }^{(21)}$; a history of malignancy ( $n$ 5379); a history of CVD ( $n$ 2119); a history of hypertension ( $n$ 19863); a history of diabetes ( $n$ 5999); alcohol intake of $\geq 20 \mathrm{~g} / \mathrm{d}$ for women or $\geq 30 \mathrm{~g} / \mathrm{d}$ for men $(n 33028)^{(21)}$; $\geq 12$ missing food items ( $n$ 38150); missing data on rice ( $n$ 33616); or implausible energy intakes $( \pm 3$ sD of the mean log-transformed energy; $n$ 25270). As a result, a total of 100177 participants were included in our study (Fig. 1). The present study was approved by the Institutional Review Board of Kangbuk Samsung Hospital. The requirement for informed consent was waived, as we used only de-identified data that were routinely collected during health screening examinations.

\section{Dietary assessment}

Dietary intake was assessed using a 106-item, self-administered FFQ designed to capture usual dietary intake of Koreans ${ }^{(22)}$. The reproducibility and validity of the FFQ were previously evaluated among 124 Korean subjects aged $40-70$ years $^{(22)}$. Participants were asked how often, on average, they had consumed each type of food or beverage over the previous 12 months. Intake of each food item was assessed in nine predefined categories of frequency, ranging from never or seldom to three or more times per day for foods and from never or seldom to five or more times per day for beverages and categories of three portion sizes. Participants were asked to report the consumption period (3, 6, 9 or 12 months) for seasonal consumption of fruits. Participants were also asked about salt intake habits with three behavioural questions $^{\text {(23): }}$ Q1, 'What do you think of your salt-eating habits', with five responses of very salty, a little salty, modestly salty, a little bland and very bland (scored as 12, 9, 6, 3 and 0, respectively); Q2, 'Do you add salt or soya sauce on cooked dishes?' with four responses of always, frequently, seldom and never (12, 8, 4 and 0 , respectively); Q3, 'Do you eat pan-fried or deep-fried food with soya sauce?' with three responses of always, sometimes and never (12, 6 and 0 , respectively). We summed up all the component scores to obtain an overall salt eating habit score

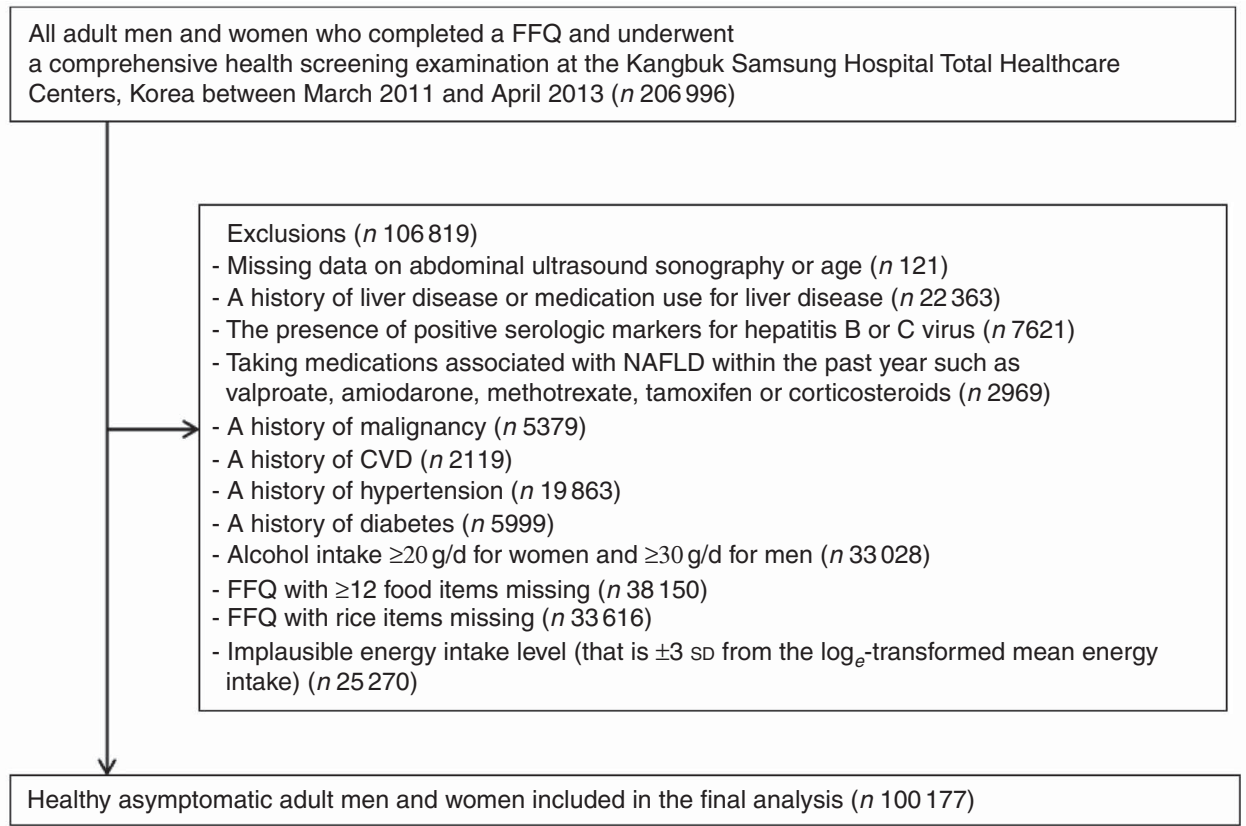

Fig. 1. Flow diagram of the study participants. NAFLD, non-alcoholic fatty liver disease. 
ranging from 0 to 36 , with higher scores indicating a higher tendency for salt usage or higher consumption of high-salt foods.

Total energy and nutrient intake was calculated on the basis of the standardised food composition database ${ }^{(24)}$. Daily intakes of $\mathrm{Na}$ and $\mathrm{K}$ were calculated by multiplying the frequency of consumption of each food by the portion size and $\mathrm{Na}$ and $\mathrm{K}$ contents of each food and summing across all relevant food items. All nutrients were energy adjusted separately for men and women using the residual regression methods ${ }^{(25)}$. When we used the nutrient density model by estimating nutrient intake per $4184 \mathrm{~kJ}$ ( $1000 \mathrm{kcal})$ of energy, we observed similar results (data not shown).

\section{Ultrasound examination of the liver}

Abdominal ultrasounds were performed using a $3 \cdot 5-\mathrm{MHz}$ transducer (Logiq 9; GE) by experienced radiologists who were unaware of the aims of the study and were blinded to the laboratory values. Images were captured in a standard manner with the health screen examinees in the supine position with the right arm raised above the head. An ultrasonographic diagnosis of fatty liver was defined as the presence of a diffuse increase in fine echoes in the liver parenchyma compared with the kidney or spleen parenchyma ${ }^{(26)}$. High inter-observer and intra-observer reliabilities for fatty liver diagnosis were achieved in our study, with $\kappa$ statistic values of 0.74 and 0.94 , respectively ${ }^{(19)}$. We defined NAFLD as the presence of fatty liver on ultrasonography in the absence of elevated alcohol consumption (a threshold of $<20 \mathrm{~g} / \mathrm{d}$ for women and $<30 \mathrm{~g} / \mathrm{d}$ for men) ${ }^{(21)}$ and other causes of liver disease as stated above in the exclusion criteria.

\section{Other variables}

A standardised, self-administered questionnaire containing questions on socio-demographics, medical history, medication use, family history, physical activity, alcohol intake and smoking habits was used. Physical activity levels were assessed using the Korean-validated version of the International Physical Activity Questionnaire short form ${ }^{(27)}$. Anthropometric components (height, weight and body composition) and BP were measured by trained nurses during the health examination, which are described in detail elsewhere ${ }^{(28)}$. Blood specimens were sampled from the antecubital vein after at least $10-\mathrm{h}$ of fasting, and measures of serum biochemical variables are described in detail elsewhere $^{(28)}$. The Laboratory Medicine Department at Kangbuk Samsung Hospital has been accredited by the Korean Society of Laboratory Medicine and participates annually in inspections and surveys performed by the Korean Association of Quality Assurance for Clinical Laboratories and the College of American Pathologists Proficiency Testing program.

\section{Statistical analysis}

A Poisson regression model with a robust error variance was used to estimate prevalence ratios (PR) and $95 \% \mathrm{CI}^{(29-31)}$ for men and women separately based on the evidence of sex interaction ( $P_{\text {for interaction }}<0.01$ for both $\mathrm{Na}$ and $\mathrm{K}$ intake). Na and $\mathrm{K}$ intakes and $\mathrm{Na}: \mathrm{K}$ ratio were categorised into sex-specific quintiles.
We fitted two models as follows: the basic model was adjusted for age and total energy intake (quintiles), and the multivariable model was further adjusted for study centre (two categories), year of screening exam (1-year categories), education level (<community college graduate, $\geq$ community college graduate or unknown), physical activity level (inactive, minimally active, health-enhancing physically active or unknown), smoking status (never, past, current or unknown), alcohol intake $(0,<10$ or $\geq 10 \mathrm{~g} / \mathrm{d})$, and intakes of energyadjusted calcium (Ca), protein and fibre (quintiles). $\mathrm{Na}$ and $\mathrm{K}$ intakes were also mutually adjusted in the model because of potential reciprocal biological effects ${ }^{(32)}$. In additional analysis, we further adjusted for intake of total fat and carbohydrates. Tests for trends were performed using the median value in each quintile and by modelling this variable as a continuous variable in the models. Exposures of interest as quantitative continuous variables were also estimated using a $1000-\mathrm{mg} / \mathrm{d}$ increase in $\mathrm{Na}$ and $\mathrm{K}$ and a 1 -unit increase in $\mathrm{Na}: \mathrm{K}$ ratio.

There has been a broad range of variation in sensitivities and specificities when comparing ultrasonography and liver biopsy as a gold standard $^{(33)}$. We conducted a series of sensitivity analyses to test the robustness of our primary results. First, we examined the associations between dietary intakes of $\mathrm{Na}$ and $\mathrm{K}$ and $\mathrm{Na}: \mathrm{K}$ ratio and prevalence of NAFLD defined by ultrasound findings along with elevated ALT levels of $>0.33 \mu \mathrm{kat} / \mathrm{l}$, which is related to NAFLD ${ }^{(21)}$. Second, we used fatty liver index (FLI), a validated surrogate marker of fatty liver, as an outcome. The FLI was calculated as $\left(e^{0.953 \times \log _{e}\left(\mathrm{TG}+0.139 \times \mathrm{BMI}+0.718 \times \log _{e}(\mathrm{ggt})+0.053 \times \text { waist circumference }-15.745\right) /}\right.$

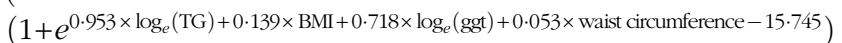
$\times 100^{(34)}$ and then categorised into three groups of FLI $<30,30$ to $<60$ and $\geq 60$. Third, we calculated the percentage contribution of each food to the total daily $\mathrm{Na}$ intake and evaluated the associations of the major food sources of $\mathrm{Na}$ intake including kimchi (combination of four kinds - Korean traditional salted and fermented vegetable dish) and ramen (instant noodle) with the prevalence of NAFLD. Finally, we examined whether the salt eating habit score, assessed by the behavioural questionnaire, was associated with the prevalence of NAFLD.

To evaluate whether these variables mediated the association between $\mathrm{Na}$ intake and prevalence of NAFLD, we further adjusted for BMI, body fat percentage (BF\%), systolic BP and homoeostasis model assessment of insulin resistance (HOMA-IR). We conducted subgroup analyses to determine whether the associations of $\mathrm{Na}$ intake with the prevalence of NAFLD were modified by age, smoking status, physical activity level, BMI or $\mathrm{BF} \%{ }^{(35)}$. The Wald's test was used to test the significance of the interaction term. In an additional sensitivity analysis, we included a history of hypertension, rather than excluding, to the model to test whether the inclusion of this variable would attenuate the estimates of interest. All $P$ values were two-tailed, and $P<0.05$ was considered to be statistically significant. We used STATA version 13.1 (StataCorp LP) for all analyses.

\section{Results}

The median age of the participants was 37.2 years (interquartile range, $32 \cdot 7-42 \cdot 1)$. The proportion of ultrasound-diagnosed 
NAFLD was $35.6 \%$ for men and $9.8 \%$ for women. The characteristics of the study participants according to energyadjusted $\mathrm{Na}$ and $\mathrm{K}$ intakes for men and women are shown in Tables 1 and 2, respectively. Men and women consuming high levels of $\mathrm{Na}$ were more likely to be current smokers, to consume more alcohol, to engage in vigorous physical activity and were less likely to be educated compared with those consuming lower levels of $\mathrm{Na}$. Similar patterns were observed for K intake except education level. TG levels increased with increasing levels of $\mathrm{Na}$ intake but not with $\mathrm{K}$ intake. Total cholesterol and LDL-cholesterol levels increased with increasing levels of $\mathrm{Na}$ and $\mathrm{K}$ intake among women, but these relationships were less clear among men. Men and women in the lowest quintile of $\mathrm{Na}$ intake tended to consume less protein, fat, $\mathrm{Ca}$ and dietary fibre but more carbohydrates compared with those in the highest quintile of $\mathrm{Na}$ intake. For dietary intake of nutrients, the similar patterns were observed for $\mathrm{K}$ intake.

In primary analyses, higher levels of energy-adjusted $\mathrm{Na}$ intake and $\mathrm{Na}: \mathrm{K}$ ratio were associated with a higher prevalence of NAFLD, with a dose-response trend (Table 3). In multivariable-adjusted analyses, compared with men in the lowest quintile of $\mathrm{Na}$ intake and $\mathrm{Na}: \mathrm{K}$ ratio, those in the highest quintile had a $25 \%$ and a $13 \%$ higher prevalence of NAFLD, respectively. Compared with women in the lowest quintile of $\mathrm{Na}$ intake and $\mathrm{Na}: \mathrm{K}$ ratio, those in the highest quintile had a $32 \%$ and a $13 \%$ greater prevalence of NAFLD, respectively. However, we observed no inverse association between $\mathrm{K}$ intake and prevalence of NAFLD in either men or women but an unexpected positive association only in men. The main results remained similar after further adjustment for intake of total fat and carbohydrates in additional analysis; the multivariable-adjusted PR comparing extreme quintiles of $\mathrm{Na}, \mathrm{K}$ and $\mathrm{Na}: \mathrm{K}$ ratio were 1.25 (95\% CI 1.18, 1.33) in men and 1.35 (95\% CI $1.21,1.50)$ in women, 1.12 (95\% CI 1.05, 1.20) in men and 1.15 (95\% CI 0.99, 1.33) in women, and 1.13 (95\% CI 1.08 , $1 \cdot 18)$ in men and 1.14 (95\% CI $1.05,1.23)$ in women, respectively.

The primary findings of the association of $\mathrm{Na}$ intake with the prevalence of ultrasound-diagnosed NAFLD were further corroborated by the results from the several sensitivity analyses: first, the results of including elevated ALT levels of $>0.33 \mu \mathrm{kat} / \mathrm{lin}$ the definition for diagnosing NAFLD based on ultrasound findings

Table 1. Characteristics of the study participants by intake of energy-adjusted sodium and potassium* in 46596 men

(Mean values and standard deviations, proportions)

\begin{tabular}{|c|c|c|c|c|c|c|c|c|c|c|c|c|}
\hline \multirow[b]{3}{*}{ Characteristics } & \multicolumn{6}{|c|}{$\mathrm{Na}$ intake } & \multicolumn{6}{|c|}{$\mathrm{K}$ intake } \\
\hline & \multicolumn{2}{|c|}{ Q1 } & \multicolumn{2}{|c|}{ Q3 } & \multicolumn{2}{|c|}{ Q5 } & \multicolumn{2}{|c|}{ Q1 } & \multicolumn{2}{|c|}{ Q3 } & \multicolumn{2}{|c|}{ Q5 } \\
\hline & Mean & SD & Mean & SD & Mean & SD & Mean & SD & Mean & SD & Mean & SD \\
\hline \multicolumn{13}{|l|}{ Men } \\
\hline $\mathrm{Na}$ (median $\mathrm{mg} / \mathrm{d}$ ) & \multicolumn{2}{|c|}{1219} & \multicolumn{2}{|c|}{2126} & \multirow{2}{*}{\multicolumn{2}{|c|}{3485}} & \multirow{2}{*}{\multicolumn{2}{|c|}{1403}} & \multirow{2}{*}{\multicolumn{2}{|c|}{2177}} & \multicolumn{2}{|c|}{2997} \\
\hline $\mathrm{K}$ (median $\mathrm{mg} / \mathrm{d}$ ) & \multicolumn{2}{|c|}{1510} & \multicolumn{2}{|c|}{1972} & & & & 1384 & & & \multicolumn{2}{|c|}{2774} \\
\hline Age (years) & 38.6 & 7.6 & 37.9 & $7 \cdot 1$ & $39 \cdot 3$ & 7.9 & 37.6 & $7 \cdot 2$ & 38.1 & 7.0 & 39.9 & 8.1 \\
\hline Current smoker (\%) & \multicolumn{2}{|c|}{29.3} & \multicolumn{2}{|c|}{33.6} & \multicolumn{2}{|c|}{37.6} & \multicolumn{2}{|c|}{30.3} & 33 & 3.8 & 35 & \\
\hline Alcohol intake of 10 to $<30 \mathrm{~g} / \mathrm{d}(\%) \dagger$ & 43 & 3.8 & $4 \varepsilon$ & 3.5 & 53 & & 46 & 9 & 47 & 7.0 & 49 & \\
\hline HEPA (\%) & & 6.7 & & .3 & & 4 & & 5.4 & & 3.7 & 11 & \\
\hline $\begin{array}{l}\text { Community college graduate or } \\
\text { higher }(\%)\end{array}$ & 73 & 3.7 & 73 & 3.0 & 71 & & 71 & $\cdot 1$ & 72 & 2.8 & 73 & \\
\hline $\mathrm{BMI}\left(\mathrm{kg} / \mathrm{m}^{2}\right)$ & $23 \cdot 6$ & $2 \cdot 8$ & $24 \cdot 0$ & $2 \cdot 8$ & $24 \cdot 2$ & $2 \cdot 8$ & $23 \cdot 6$ & $2 \cdot 8$ & $24 \cdot 0$ & $2 \cdot 8$ & $24 \cdot 2$ & $2 \cdot 7$ \\
\hline $\mathrm{BF} \%$ & $21 \cdot 6$ & $5 \cdot 2$ & 22.0 & 5.4 & $22 \cdot 2$ & $5 \cdot 2$ & $21 \cdot 7$ & $5 \cdot 3$ & 22.0 & $5 \cdot 3$ & $22 \cdot 1$ & $5 \cdot 3$ \\
\hline Systolic BP (mmHg) & 112.5 & $10 \cdot 9$ & $113 \cdot 1$ & $11 \cdot 1$ & 113.8 & $11 \cdot 2$ & $113 \cdot 1$ & $10 \cdot 9$ & $113 \cdot 2$ & 11.1 & $113 \cdot 3$ & $11 \cdot 2$ \\
\hline Diastolic BP (mmHg) & $71 \cdot 8$ & $8 \cdot 8$ & 71.9 & $8 \cdot 7$ & $72 \cdot 7$ & $9 \cdot 0$ & $72 \cdot 1$ & $8 \cdot 7$ & $72 \cdot 1$ & 8.9 & $72 \cdot 3$ & 9.0 \\
\hline Glucose $(\mathrm{mmol} / \mathrm{l})$ & $5 \cdot 28$ & 0.55 & $5 \cdot 29$ & 0.58 & 5.34 & 0.68 & $5 \cdot 28$ & 0.57 & $5 \cdot 29$ & 0.62 & 5.33 & 0.64 \\
\hline Insulin (pmol/l) & $38 \cdot 2$ & $24 \cdot 3$ & $38 \cdot 2$ & $23 \cdot 6$ & 37.5 & 23.6 & $38 \cdot 2$ & $24 \cdot 3$ & $38 \cdot 2$ & $23 \cdot 6$ & $36 \cdot 8$ & $22 \cdot 9$ \\
\hline HOMA-IR & $1 \cdot 32$ & 0.93 & 1.32 & 0.91 & 1.32 & 0.90 & 1.33 & 0.91 & 1.33 & 0.91 & 1.29 & 0.86 \\
\hline Total cholesterol $(\mathrm{mmol} / \mathrm{l})$ & $5 \cdot 12$ & 0.87 & $5 \cdot 14$ & 0.86 & $5 \cdot 17$ & 0.87 & $5 \cdot 10$ & 0.87 & 5.14 & 0.86 & $5 \cdot 16$ & 0.86 \\
\hline LDL-cholesterol (mmol/l) & $3 \cdot 30$ & 0.80 & $3 \cdot 30$ & 0.80 & 3.33 & 0.80 & $3 \cdot 27$ & 0.80 & 3.31 & 0.79 & 3.32 & 0.79 \\
\hline HDL-cholesterol (mmol/l/) & 1.37 & 0.32 & 1.37 & 0.32 & 1.36 & 0.32 & 1.37 & 0.32 & 1.37 & 0.32 & 1.38 & 0.33 \\
\hline $\mathrm{TG}(\mathrm{mmol} / \mathrm{l})$ & 1.37 & 0.86 & 1.39 & 0.82 & 1.46 & 0.89 & 1.39 & 0.88 & 1.41 & 0.86 & 1.40 & 0.82 \\
\hline ALT $(\mu \mathrm{kat} / \mathrm{l})$ & 0.44 & 0.31 & 0.45 & 0.30 & 0.46 & 0.30 & 0.45 & 0.32 & 0.46 & 0.31 & 0.45 & 0.29 \\
\hline AST $(\mu k a t / l)$ & 0.38 & 0.18 & 0.38 & 0.18 & 0.39 & 0.19 & 0.38 & $0 \cdot 18$ & 0.38 & 0.17 & 0.39 & 0.19 \\
\hline GGT $(\mu k a t /)$ & 0.55 & 0.47 & 0.56 & 0.51 & 0.62 & 0.54 & 0.57 & 0.49 & 0.58 & 0.49 & 0.58 & 0.53 \\
\hline Dietary intake* & & & & & & & & & & & & \\
\hline Total energy $(\mathrm{kJ} / \mathrm{d})$ & 7305 & 2121 & 7770 & 2460 & 7389 & 2448 & 7284 & 2138 & 7673 & 2330 & 7494 & 2732 \\
\hline Total energy (kcal/d) & 1746 & 507 & 1857 & 588 & 1766 & 585 & 1741 & 511 & 1834 & 557 & 1791 & 653 \\
\hline Protein $(\mathrm{g} / \mathrm{d})$ & $55 \cdot 0$ & 8.0 & $62 \cdot 3$ & 9.5 & $66 \cdot 4$ & $11 \cdot 0$ & 53.0 & $6 \cdot 6$ & 61.5 & $8 \cdot 1$ & $70 \cdot 2$ & $11 \cdot 2$ \\
\hline Total fat $(\mathrm{g} / \mathrm{d})$ & 30.0 & 9.8 & 37.1 & $11 \cdot 1$ & $36 \cdot 6$ & $11 \cdot 2$ & 28.9 & 9.5 & $36 \cdot 1$ & $10 \cdot 1$ & $40 \cdot 2$ & 11.6 \\
\hline Carbohydrates (g/d) & 321.0 & $26 \cdot 7$ & 301.7 & $30 \cdot 2$ & 301.1 & 30.9 & 324.6 & $24 \cdot 3$ & $304 \cdot 1$ & $27 \cdot 6$ & 291.6 & $33 \cdot 2$ \\
\hline $\mathrm{Ca}(\mathrm{mg} / \mathrm{d})$ & $292 \cdot 1$ & $118 \cdot 2$ & $398 \cdot 1$ & $136 \cdot 2$ & $500 \cdot 2$ & 171.4 & 251.3 & $78 \cdot 3$ & 385.6 & 97.4 & $568 \cdot 1$ & $177 \cdot 0$ \\
\hline Dietary fibre $(\mathrm{g} / \mathrm{d})$ & $3 \cdot 2$ & 0.9 & $4 \cdot 4$ & 1.0 & $6 \cdot 6$ & 1.8 & 3.1 & 0.8 & 4.4 & 1.0 & 6.5 & $2 \cdot 0$ \\
\hline $\mathrm{Na}: \mathrm{K}$ ratio & 0.8 & 0.2 & $1 \cdot 1$ & 0.2 & 1.5 & 0.3 & $1 \cdot 1$ & 0.3 & 1.1 & 0.3 & $1 \cdot 1$ & 0.4 \\
\hline
\end{tabular}

HEPA, health-enhancing physical activity; BF\%, body fat percentage; BP, blood pressure; HOMA-IR, homoeostasis model assessment of insulin resistance; ALT, alanine aminotransferase; AST, aspartate amniotransferase; GGT, $\gamma$-glutamyl transferase.

* Nutrients were adjusted for total energy intake using the residual method in the distribution of 46596 men eligible for the analyses.

$\dagger$ Excessive alcohol intake was excluded on the basis of exclusion criteria ( $\geq 30 \mathrm{~g} / \mathrm{d}$ for men or $\geq 20 \mathrm{~g} / \mathrm{d}$ for women). 
Table 2. Characteristics of the study participants by intake of energy-adjusted sodium and potassium* in 53581 women (Mean values and standard deviations, proportions)

\begin{tabular}{|c|c|c|c|c|c|c|c|c|c|c|c|c|}
\hline \multirow[b]{3}{*}{ Characteristics } & \multicolumn{6}{|c|}{$\mathrm{Na}$ intake } & \multicolumn{6}{|c|}{$\mathrm{K}$ intake } \\
\hline & \multicolumn{2}{|c|}{ Q1 } & \multicolumn{2}{|c|}{ Q3 } & \multicolumn{2}{|c|}{ Q5 } & \multicolumn{2}{|c|}{ Q1 } & \multicolumn{2}{|c|}{ Q3 } & \multicolumn{2}{|c|}{ Q5 } \\
\hline & Mean & SD & Mean & SD & Mean & SD & Mean & SD & Mean & SD & Mean & SD \\
\hline \multicolumn{13}{|l|}{ Women } \\
\hline $\mathrm{Na}$ (median mg/d) & \multicolumn{2}{|c|}{1077} & \multicolumn{2}{|c|}{1902} & \multicolumn{2}{|c|}{3310} & \multicolumn{2}{|c|}{1264} & \multicolumn{2}{|c|}{1969} & \multicolumn{2}{|c|}{2764} \\
\hline $\mathrm{K}$ (median $\mathrm{mg} / \mathrm{d}$ ) & \multicolumn{2}{|c|}{1499} & \multicolumn{2}{|c|}{1981} & \multicolumn{2}{|c|}{2534} & \multicolumn{2}{|c|}{1347} & \multicolumn{2}{|c|}{1968} & \multicolumn{2}{|c|}{2896} \\
\hline Age (years) & $37 \cdot 6$ & 7.4 & 38.2 & $7 \cdot 6$ & $40 \cdot 2$ & 8.3 & $37 \cdot 3$ & 7.5 & 38.1 & 7.4 & $40 \cdot 6$ & 8.3 \\
\hline Current smoker (\%) & \multicolumn{2}{|c|}{1.5} & \multicolumn{2}{|c|}{1.9} & \multicolumn{2}{|c|}{1.9} & \multicolumn{2}{|c|}{1.5} & 1. & 8 & 2. & \\
\hline Alcohol intake of 10 to $<20 \mathrm{~g} / \mathrm{d}(\%) \dagger$ & 8 . & 7 & 9 & 6 & 11 & $\cdot 1$ & 9 & 5 & 9. & 6 & 10 & \\
\hline HEPA (\%) & 5 . & 5 & 6 & 8 & 8. & 6 & 4 & 5 & 5 & 8 & 10 & \\
\hline Community college graduate or & 66 & 8.8 & 65 & 3 & 57 & 0 & 62 & 6 & 64 & 1.5 & 62 & \\
\hline $\begin{array}{l}\text { nigner }(\%) \\
\mathrm{BMI}\left(\mathrm{kg} / \mathrm{m}^{2}\right)\end{array}$ & $21 \cdot 1$ & $2 \cdot 7$ & 21.4 & $2 \cdot 8$ & $21 \cdot 8$ & $2 \cdot 9$ & $21 \cdot 1$ & $2 \cdot 8$ & 21.4 & $2 \cdot 8$ & $21 \cdot 7$ & 2.8 \\
\hline $\mathrm{BF} \%$ & $28 \cdot 3$ & $5 \cdot 7$ & $28 \cdot 7$ & $5 \cdot 7$ & $29 \cdot 1$ & 5.9 & 28.5 & $5 \cdot 7$ & $28 \cdot 7$ & $5 \cdot 7$ & $28 \cdot 7$ & $5 \cdot 8$ \\
\hline Systolic BP (mmHg) & $100 \cdot 9$ & $10 \cdot 9$ & 101.9 & 11.4 & $103 \cdot 2$ & 11.8 & 101.6 & $11 \cdot 1$ & $101 \cdot 7$ & $11 \cdot 1$ & $102 \cdot 7$ & 11.8 \\
\hline Diastolic BP (mmHg) & $64 \cdot 3$ & 8.0 & $64 \cdot 8$ & 8.3 & 65.6 & 8.4 & 64.7 & 8.0 & $64 \cdot 7$ & $8 \cdot 0$ & $65 \cdot 3$ & 8.6 \\
\hline Glucose $(\mathrm{mmol} / \mathrm{l})$ & 5.04 & 0.50 & 5.07 & 0.51 & $5 \cdot 12$ & 0.59 & 5.06 & 0.51 & 5.07 & 0.51 & 5.09 & 0.53 \\
\hline Insulin (pmol//) & 34.7 & $23 \cdot 6$ & 35.4 & $24 \cdot 3$ & 34.7 & 21.5 & 35.4 & 21.5 & 34.7 & 21.5 & 33.3 & 21.5 \\
\hline HOMA-IR & $1 \cdot 14$ & 0.83 & $1 \cdot 16$ & 0.89 & $1 \cdot 16$ & 0.82 & $1 \cdot 16$ & 0.78 & 1.16 & 0.81 & $1 \cdot 11$ & 0.83 \\
\hline Total cholesterol $(\mathrm{mmol} / \mathrm{l})$ & 4.80 & 0.84 & 4.85 & 0.85 & 4.89 & 0.85 & 4.78 & 0.83 & 4.84 & 0.83 & 4.91 & 0.86 \\
\hline LDL-cholesterol $\left(\mathrm{mmol} / \mathrm{l}^{\prime}\right.$ & $2 \cdot 80$ & 0.75 & 2.85 & 0.77 & 2.91 & 0.78 & $2 \cdot 80$ & 0.75 & 2.85 & 0.75 & 2.91 & 0.79 \\
\hline HDL-cholesterol $(\mathrm{mmol} / \mathrm{l})$ & 1.68 & 0.37 & 1.69 & 0.37 & 1.66 & 0.37 & 1.67 & 0.37 & 1.68 & 0.37 & 1.69 & 0.38 \\
\hline $\mathrm{TG}(\mathrm{mmol} / \mathrm{l})$ & 0.90 & 0.48 & 0.91 & 0.49 & 0.95 & 0.52 & 0.91 & 0.48 & 0.91 & 0.48 & 0.92 & 0.53 \\
\hline ALT $(\mu k a t / /)$ & 0.25 & 0.23 & 0.25 & 0.17 & 0.26 & $0 \cdot 19$ & 0.25 & 0.16 & 0.25 & $0 \cdot 18$ & 0.27 & 0.27 \\
\hline AST ( $\mu \mathrm{kat} / \mathrm{l})$ & 0.30 & 0.13 & 0.31 & 0.12 & 0.31 & $0 \cdot 13$ & 0.30 & 0.14 & 0.31 & 0.14 & 0.32 & 0.18 \\
\hline GGT ( $\mu \mathrm{kat} / \mathrm{l})$ & 0.26 & 0.23 & 0.26 & 0.22 & 0.28 & 0.24 & 0.26 & 0.22 & 0.26 & 0.20 & 0.28 & 0.27 \\
\hline Dietary intake & & & & & & & & & & & & \\
\hline Total energy $(\mathrm{kJ} / \mathrm{d})$ & 6473 & 2050 & 6841 & 2452 & 6577 & 2494 & 6431 & 2013 & 6841 & 2284 & 6657 & 2741 \\
\hline Total energy (kcal/d) & 1547 & 490 & 1635 & 586 & 1572 & 596 & 1537 & 481 & 1635 & 546 & 1591 & 655 \\
\hline Protein $(\mathrm{g} / \mathrm{d})$ & $49 \cdot 0$ & 7.4 & $55 \cdot 7$ & $8 \cdot 8$ & $60 \cdot 1$ & $10 \cdot 9$ & $47 \cdot 2$ & 6.0 & $54 \cdot 8$ & 7.4 & 63.2 & 11.0 \\
\hline Total fat $(\mathrm{g} / \mathrm{d})$ & 26.9 & 9.5 & 33.4 & $10 \cdot 3$ & $32 \cdot 3$ & $10 \cdot 4$ & $26 \cdot 0$ & $9 \cdot 3$ & $32 \cdot 1$ & 9.9 & $35 \cdot 3$ & $10 \cdot 6$ \\
\hline Carbohydrates $(g / d)$ & 285.9 & $25 \cdot 4$ & 268.4 & $28 \cdot 1$ & $268 \cdot 8$ & $29 \cdot 7$ & 288.3 & $23 \cdot 2$ & 271.4 & $26 \cdot 6$ & 261.9 & 31.9 \\
\hline $\mathrm{Ca}(\mathrm{mg} / \mathrm{d})$ & $307 \cdot 1$ & $136 \cdot 1$ & $417 \cdot 8$ & $156 \cdot 8$ & 535.4 & $209 \cdot 0$ & 254.9 & $83 \cdot 7$ & 399.6 & 107.7 & $618 \cdot 7$ & $210 \cdot 4$ \\
\hline Dietary fibre $(g / d)$ & 3.3 & $1 \cdot 1$ & 4.5 & 1.3 & 6.9 & $2 \cdot 1$ & 3.1 & 0.8 & 4.5 & 1.0 & $7 \cdot 1$ & 2.2 \\
\hline Na:K ratio & 0.7 & 0.2 & 1.0 & 0.2 & 1.4 & 0.3 & 1.0 & 0.3 & 1.0 & 0.3 & 1.0 & 0.4 \\
\hline
\end{tabular}

HEPA, health-enhancing physical activity; BF\%, body fat percentage; BP, blood pressure; HOMA-IR, homoeostasis model assessment of insulin resistance; ALT, alanine aminotransferase; AST, aspartate amniotransferase; GGT, $\gamma$-glutamyl transferase.

* Nutrients were adjusted for total energy intake using the residual method in the distribution of 53581 women eligible for the analyses.

$\dagger$ Excessive alcohol intake was excluded on the basis of exclusion criteria ( $\geq 30 \mathrm{~g} / \mathrm{d}$ for men or $\geq 20 \mathrm{~g} / \mathrm{d}$ for women).

were consistent with the findings of the primary analysis (online Supplementary Table S1). Second, we found a positive association of FLI with $\mathrm{Na}$ intake but not with $\mathrm{K}$ intake (online Supplementary Table S2). Third, when we examined the first and the second largest food sources of $\mathrm{Na}$ in our data $(47.5 \%$ for kimchi and $8.0 \%$ for ramen), we consistently found their positive associations with the prevalence of NAFLD. The multivariable-adjusted PR of NAFLD for the highest compared with the lowest tertiles of kimchi were 1.04 (95\% CI 1.00, 1.07; $\left.P_{\text {trend }}=0.03\right)$ in men and 1.09 (95\% CI 1.02, 1.16; $\left.P_{\text {trend }}=0.02\right)$ in women. The multivariable-adjusted PR of NAFLD for the highest compared with the lowest tertiles of ramen were 1.13 (95\% CI $\left.1.08,1 \cdot 18 ; P_{\text {trend }}<0.001\right)$ in men and $1.21(95 \%$ CI $1.13,1 \cdot 29$; $\left.P_{\text {trend }}<0.001\right)$ in women. Fourth, when we examined the relationship between salt eating habit score and prevalence of NAFLD, we found that men and women reporting a higher salt eating habit score had a higher prevalence of NAFLD; the multivariable-adjusted PR of NAFLD comparing the highest with the lowest quintiles of salt eating habit score were 1.21 (95\% CI 1.16, 1.26; $P_{\text {trend }}<0.001$ ) for men and 1.22 (95\% CI 1.11, 1.33; $\left.P_{\text {trend }}<0.001\right)$ for women. We also found that those who consumed higher levels of Na tended to have a higher salt eating habit score $\left(P_{\text {trend }}<0.001\right.$ for men and women). In an additional sensitivity analysis, where we included a history of hypertension in the multivariable model instead of excluding it, we found that the estimates did not change appreciably (data not shown).

When we examined whether the association between $\mathrm{Na}$ intake and NAFLD was mediated by metabolic parameters, we found that the association was substantially attenuated after further adjustment for BMI or BF\%, whereas the association was not considerably changed after adjustment for systolic BP or HOMA-IR (Table 4). When we stratified the analysis by indicators of adiposity, we consistently found a positive association between $\mathrm{Na}$ intake and prevalence of NAFLD in low and high body weight participants (BMI $\geq 23 \mathrm{~kg} / \mathrm{m}^{2}$ or $\mathrm{BF} \% \geq 23 \%$ in men and $\geq 35 \%$ in women; online Supplementary Table S3).

\section{Discussion}

In this large sample of young and middle-aged asymptomatic men and women, we found that high $\mathrm{Na}$ intake was associated with a greater prevalence of ultrasound-diagnosed NAFLD after 
Table 3. Prevalence ratios (PR) of non-alcoholic fatty liver disease (NAFLD) by intake of energy-adjusted sodium and potassium and sodium:potassium ratio $†$ (PR and $95 \%$ confidence intervals)

\begin{tabular}{|c|c|c|c|c|c|c|c|c|c|c|c|c|}
\hline & \multicolumn{9}{|c|}{ Quintiles of intake } & \multirow[b]{3}{*}{$P_{\text {for trend }}$} & & \\
\hline & \multirow{2}{*}{$\begin{array}{l}\text { Q1 } \\
\text { PR }\end{array}$} & \multicolumn{2}{|r|}{ Q2 } & \multicolumn{2}{|r|}{ Q3 } & \multicolumn{2}{|r|}{ Q4 } & \multicolumn{2}{|r|}{ Q5 } & & \multicolumn{2}{|c|}{ Continuous $\ddagger$} \\
\hline & & PR & $95 \% \mathrm{Cl}$ & PR & $95 \% \mathrm{Cl}$ & PR & $95 \% \mathrm{Cl}$ & PR & $95 \% \mathrm{Cl}$ & & PR & $95 \% \mathrm{Cl}$ \\
\hline \multicolumn{13}{|l|}{ Men } \\
\hline \multicolumn{13}{|l|}{$\mathrm{Na \S}$} \\
\hline Median $(\mathrm{mg} / \mathrm{d})$ & 1219 & & 1697 & & 2126 & & 2641 & & 3485 & & & \\
\hline No. of cases & 3185 & & 3344 & & 3271 & & 3364 & & 3419 & & & \\
\hline Age- and energy-adjusted & 1.00 (Ref.) & 1.06 & $1 \cdot 02,1 \cdot 10$ & 1.03 & $0.99,1.08$ & 1.06 & $1 \cdot 02,1 \cdot 11$ & 1.08 & $1.03,1.13$ & 0.006 & 1.03 & $1.01,1.04$ \\
\hline Multivariable-adjusted & 1.00 (Ref.) & 1.09 & $1.05,1 \cdot 14$ & $1 \cdot 11$ & $1.06,1 \cdot 16$ & $1 \cdot 18$ & $1 \cdot 12,1.24$ & 1.25 & $1.18,1.32$ & $<0.001$ & 1.07 & $1.06,1.09$ \\
\hline \multicolumn{13}{|c|}{ 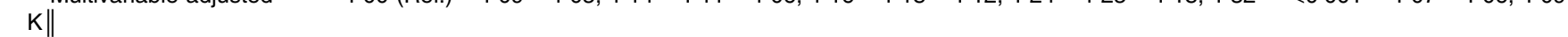 } \\
\hline Median (mg/d) & 1384 & & 1718 & & 1977 & & 2270 & & 2774 & & & \\
\hline No. of cases & 3224 & & 3261 & & 3377 & & 3371 & & 3350 & & & \\
\hline Age- and energy-adjusted & 1.00 (Ref.) & 0.99 & $0.95,1.03$ & 1.01 & $0.97,1.06$ & 1.00 & $0.95,1.04$ & 0.96 & $0.92,1.01$ & 0.13 & 0.98 & $0.96,1.01$ \\
\hline Multivariable-adjusted & 1.00 (Ref.) & 1.03 & $0.99,1.08$ & 1.09 & $1.04,1.14$ & $1 \cdot 11$ & $1.05,1 \cdot 18$ & $1 \cdot 12$ & $1.05,1.20$ & $<0.001$ & 1.07 & $1.03,1.11$ \\
\hline \multicolumn{13}{|l|}{ Na:K ratio } \\
\hline Median (ratio) & 0.7 & & 0.9 & & $1 \cdot 1$ & & 1.3 & & 1.6 & & & \\
\hline No. of cases & 3192 & & 3332 & & 3376 & & 3315 & & 3368 & & & \\
\hline Age- and energy-adjusted & 1.00 (Ref.) & 1.06 & $1.01,1 \cdot 10$ & 1.07 & $1.03,1.12$ & 1.06 & $1.01,1.10$ & 1.07 & $1.03,1 \cdot 11$ & 0.003 & 1.05 & $1.02,1.09$ \\
\hline Multivariable-adjusted & 1.00 (Ref.) & 1.06 & $1 \cdot 02,1 \cdot 10$ & 1.09 & $1 \cdot 05,1 \cdot 13$ & 1.09 & $1.04,1 \cdot 13$ & $1 \cdot 13$ & $1.08,1 \cdot 18$ & $<0.001$ & $1 \cdot 12$ & $1.07,1.16$ \\
\hline \multicolumn{13}{|c|}{ 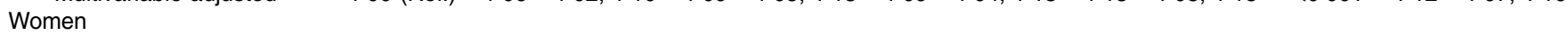 } \\
\hline \multicolumn{13}{|l|}{$\mathrm{Na \S}$} \\
\hline Median (mg/d) & 1077 & & 1502 & & 1902 & & 2397 & & 3310 & & & \\
\hline No. of cases & 930 & & 898 & & 1050 & & 1094 & & 1259 & & & \\
\hline Age- and energy-adjusted & 1.00 (Ref.) & 0.97 & $0.88,1.05$ & $1 \cdot 10$ & $1.00,1.20$ & 1.09 & $1.00,1.20$ & 1.22 & $1.11,1.35$ & $<0.001$ & 1.07 & $1.04,1.10$ \\
\hline Multivariable-adjusted & 1.00 (Ref.) & 0.98 & $0.89,1.07$ & 1.13 & $1.03,1.24$ & $1 \cdot 14$ & $1.04,1.26$ & 1.32 & $1.18,1.47$ & $<0.001$ & 1.09 & $1.05,1.12$ \\
\hline \multicolumn{13}{|l|}{$\mathrm{K} \|$} \\
\hline Median (mg/d) & 1347 & & 1686 & & 1968 & & 2296 & & 2896 & & & \\
\hline No. of cases & 944 & & 1008 & & 1017 & & 1107 & & 1155 & & & \\
\hline Age- and energy-adjusted & 1.00 (Ref.) & 1.01 & $0.92,1.10$ & 0.95 & $0.87,1.04$ & 0.95 & $0.87,1.04$ & 0.87 & $0.79,0.96$ & 0.001 & 0.93 & $0.88,0.97$ \\
\hline Multivariable-adjusted & 1.00 (Ref.) & 1.06 & $0.96,1.16$ & 1.05 & $0.94,1.17$ & $1 \cdot 12$ & $0.99,1.26$ & $1 \cdot 11$ & $0.97,1.29$ & 0.16 & 1.04 & $0.97,1.11$ \\
\hline \multicolumn{13}{|l|}{$\mathrm{Na}: \mathrm{K}$ ratio } \\
\hline Median (ratio) & 0.6 & & 0.8 & & 1.0 & & 1.2 & & 1.5 & & & \\
\hline No. of cases & 992 & & 938 & & 1042 & & 1072 & & 1187 & & & \\
\hline Age- and energy-adjusted & 1.00 (Ref.) & 0.96 & $0.88,1.05$ & 1.05 & $0.97,1.14$ & 1.07 & $0.99,1.16$ & $1 \cdot 15$ & $1.06,1.24$ & $<0.001$ & $1 \cdot 18$ & $1.10,1.27$ \\
\hline Multivariable-adjusted & 1.00 (Ref.) & 0.94 & $0.87,1.03$ & 1.03 & $0.95,1.11$ & 1.05 & $0.97,1.14$ & 1.13 & $1.04,1.22$ & $<0.001$ & $1 \cdot 18$ & $1 \cdot 10,1 \cdot 27$ \\
\hline
\end{tabular}

Ref. referent values.

* Estimated from a Poisson regression model with a robust error variance using a binary outcome variable (presence or absence). The multivariable-adjusted model was adjusted for age, total energy intake (quintiles), study centre (two categories), year of screening exam (1-year categories), education level (<community college, $\geq$ community college graduate or unknown), physical activity level (inactive, minimally active, HEPA or unknown), smoking status (never, past, current or unknown), alcohol intake ( $0,<10$ or $\geq 10$ g/d) and intakes of energy-adjusted $\mathrm{Ca}$, protein and fibre (quintiles).

† The overall interactions between sex and $\mathrm{Na}$ and $\mathrm{K}$ intakes in relation to the prevalence of NAFLD were $<0.01$ in the multivariate-adjusted model.

$\ddagger$ Based on a $1000-\mathrm{mg} / \mathrm{d}$ increment of $\mathrm{Na}$ and $\mathrm{K}$ intake and a 1-unit increment in Na:K ratio.

$\S$ Additionally adjusted for quintiles of energy-adjusted $\mathrm{K}$ intake.

|| Additionally adjusted for quintiles of energy-adjusted $\mathrm{Na}$ intake.

adjustment for a variety of lifestyle and dietary factors. Additional adjustment for $\mathrm{BMI}$ and $\mathrm{BF} \%$ greatly attenuated the association, suggesting that adiposity partially mediates this association. A series of sensitivity analyses further support our primary findings; both major Na-containing food items and a high salt eating habit score were associated with a high NAFLD prevalence, and the results of FLI or ultrasound-diagnosed NAFLD along with serum ALT were consistent with the findings of our primary analysis. We did not observe a statistically significant inverse association between $\mathrm{K}$ intake and prevalence of NAFLD.

Only one study to date has evaluated the relationship between $\mathrm{Na}$ intake and NAFLD; however, that study did not evaluate whether $\mathrm{K}$ intake or Na:K ratio was associated with NAFLD and used outcomes estimated indirectly by predictive algorithms ${ }^{(36)}$. Indeed, they could not account for detailed information on physical activity level, which might be an important factor for NAFLD ${ }^{(37)}$. They conducted a cross-sectional study of 27433 subjects (mean age 51.5 years) from the Korea National Health and Nutrition Examination Surveys and found that high Na intake, estimated by spot analysis of 24-h urinary $\mathrm{Na}$ excretion, was associated with a high odds of surrogate indicators of NAFLD and advanced liver fibrosis. Consistent with this study, our findings further confirmed that $\mathrm{Na}$ intake was associated with ultrasound-diagnosed NAFLD and FLI.

There have been several studies suggesting that $\mathrm{Na}$ intake is associated with detrimental metabolic health outcomes including large body size and fatness ${ }^{(11-13)}$, insulin resistance ${ }^{(9)}$, diabetes $^{(10)}, \mathrm{BP}^{(38)}$ and $\mathrm{CVD}^{(39)}$. In addition to the sole effect of $\mathrm{Na}$ or $\mathrm{K}$ intake, the $\mathrm{Na}: \mathrm{K}$ ratio has also been proposed as an important dietary component in the dietary guidelines ${ }^{(40,41)}$. Several epidemiological studies have found that the Na:K ratio is associated with $\mathrm{BP}^{(42)}$, hypertension ${ }^{(43)}$, CVD events and mortality ${ }^{(44-47)}$, with some showing relatively stronger associations with $\mathrm{Na}: \mathrm{K}$ ratio than with $\mathrm{Na}$ or $\mathrm{K}$ intake, due to the 
Table 4. Prevalence ratios (PR)* of non-alcoholic fatty liver disease by intake of energy-adjusted sodium after adjustment for selected intermediate variables (PR and $95 \%$ confidence intervals)

\begin{tabular}{|c|c|c|c|c|c|c|c|c|c|c|}
\hline & \multicolumn{9}{|c|}{ Quintiles of intake } & \multirow[b]{3}{*}{$P_{\text {for trend }}$} \\
\hline & \multirow{2}{*}{$\begin{array}{l}\text { Q1 } \\
\text { PR } \\
\end{array}$} & \multicolumn{2}{|r|}{ Q2 } & \multicolumn{2}{|c|}{ Q3 } & \multicolumn{2}{|r|}{ Q4 } & \multicolumn{2}{|r|}{ Q5 } & \\
\hline & & PR & $95 \% \mathrm{Cl}$ & PR & $95 \% \mathrm{Cl}$ & PR & $95 \% \mathrm{Cl}$ & PR & $95 \% \mathrm{Cl}$ & \\
\hline \multicolumn{11}{|l|}{ Men } \\
\hline Multivariable-adjusted $\dagger$ & 1.00 (Ref.) & 1.09 & $1.05,1.14$ & $1 \cdot 11$ & $1.06,1.16$ & $1 \cdot 18$ & $1 \cdot 12,1 \cdot 24$ & 1.25 & $1.18,1.32$ & $<0.001$ \\
\hline Plus BMI & 1.00 (Ref.) & 1.06 & $1.02,1.11$ & 1.06 & $1.02,1.11$ & $1 \cdot 12$ & $1.07,1.17$ & $1 \cdot 16$ & $1 \cdot 10,1.22$ & $<0.001$ \\
\hline Plus BF\% & 1.00 (Ref.) & 1.05 & $1.01,1.09$ & 1.04 & $0.99,1.09$ & $1 \cdot 11$ & $1.06,1 \cdot 16$ & $1 \cdot 15$ & $1.09,1.21$ & $<0.001$ \\
\hline Plus systolic BP & 1.00 (Ref.) & 1.08 & $1.04,1.13$ & 1.09 & $1.04,1.14$ & $1 \cdot 15$ & $1 \cdot 10,1 \cdot 21$ & $1 \cdot 22$ & $1 \cdot 16,1 \cdot 29$ & $<0.001$ \\
\hline Plus HOMA-IR & 1.00 (Ref.) & $1 \cdot 11$ & $1.06,1.17$ & $1 \cdot 13$ & $1.07,1.19$ & $1 \cdot 17$ & $1.09,1.26$ & 1.25 & $1 \cdot 17,1.34$ & $<0.001$ \\
\hline \multicolumn{11}{|l|}{ Women } \\
\hline Multivariable-adjusted $\dagger$ & 1.00 (Ref.) & 0.98 & $0.89,1.07$ & $1 \cdot 13$ & $1.03,1.24$ & $1 \cdot 14$ & $1.04,1.26$ & $1 \cdot 32$ & $1.18,1.47$ & $<0.001$ \\
\hline Plus BMI & 1.00 (Ref.) & 0.93 & $0.85,1.02$ & 1.06 & $0.97,1.16$ & 0.99 & $0.90,1.10$ & $1 \cdot 11$ & $0.99,1.24$ & 0.02 \\
\hline Plus BF\% & 1.00 (Ref.) & 0.95 & $0.87,1.03$ & 1.03 & $0.95,1.13$ & 0.98 & $0.89,1.08$ & 1.06 & $0.95,1.17$ & $0 \cdot 16$ \\
\hline Plus systolic BP & 1.00 (Ref.) & 0.95 & $0.87,1.04$ & 1.08 & $0.98,1.18$ & $1 \cdot 10$ & $0.99,1.21$ & $1 \cdot 24$ & $1 \cdot 11,1.38$ & $<0.001$ \\
\hline Plus HOMA-IR & 1.00 (Ref.) & 0.99 & $0.90,1 \cdot 10$ & $1 \cdot 10$ & $0.97,1.24$ & $1 \cdot 16$ & $1.05,1.29$ & $1 \cdot 34$ & $1 \cdot 20,1 \cdot 50$ & $<0.001$ \\
\hline
\end{tabular}

Ref. referent values; BF\%, body fat percentage; BP, blood pressure; HOMA-IR, homoeostasis model assessment of insulin resistance.

* Estimated from a Poisson regression model with a robust error variance using a binary outcome variable (presence or absence). The model was further adjusted for an individual intermediate variable in addition to the covariates used in the multivariate model in Table 3: age, total energy intake (quintiles), study centre (two categories), year of screening exam (1-year categories), education level (<community college, $\geq$ community college graduate or unknown), physical activity level (inactive, minimally active, HEPA or unknown), smoking status (never, past, current or unknown), alcohol intake $(0,<10$ or $\geq 10 \mathrm{~g} / \mathrm{d}$ ) and intakes of energy-adjusted Ca, protein, fibre and $\mathrm{K}$ (quintiles)

† Estimates obtained with the multivariable-adjusted model as shown in Table 3.

Note: some variables have missing data: BMI (0.11\%), BF\% (0.19\%), systolic BP (0.45\%) and HOMA-IR (0.98\%)

biological plausibility of the possible opposite relationship between $\mathrm{Na}$ and $\mathrm{K}$ intake $32,43,46,47)$.

Greater $\mathrm{K}$ intake has been associated with lower risk of health outcomes, including all-cause and cardiovascular mortality ${ }^{(46)}$, CVD events ${ }^{(48)}$ and the metabolic syndrome ${ }^{(17)}$; however, the results regarding diabetes are inconsistent ${ }^{(10,14-16)}$. Our study showed no inverse association between $\mathrm{K}$ intake and prevalence of NALFD. Although the reason for the lack of an inverse association between $\mathrm{K}$ intake and NAFLD prevalence remains unclear, several possibilities might explain our findings. Misclassification of $\mathrm{K}$ intake assessed through the FFQ and the potential presence of residual or unmeasured confounding factors may be present. In addition, there is an overlap between the major sources of $\mathrm{Na}$ and $\mathrm{K}$ intake in the Korean diet. A traditional Korean diet, in general, contains relatively high amounts of $\mathrm{Na}$, and vegetables are usually consumed cooked with salty seasonings. The largest contributor to total daily $\mathrm{K}$ intake in the Korean diet is vegetables (24.4\%), especially cabbage kimchi, which is a traditional Korean salted and fermented vegetable dish $^{(49)}$. Similarly, in our study, the greatest contribution to total daily $\mathrm{K}$ intake was from cabbage kimchi (10.8\%). Therefore, it is plausible that a relatively large contribution of fermented and salted vegetable intake to daily total $\mathrm{K}$ intake might dilute or counteract the beneficial effect of $\mathrm{K}$ intake on NAFLD in our data. Finally, it is possible that there is truly no association between $\mathrm{K}$ intake and NAFLD.

The higher prevalence of NAFLD associated with a greater $\mathrm{Na}$ intake is not completely understood; however, there was a suggestion that increased adiposity could be the potential mechanism. In animal model studies, $\mathrm{Na}$ intake has been suggested to directly contribute to the development of obesity, given the observation that chronic salt overload induced adipocyte hypertrophy by enhancing adipocyte insulin sensitivity for glucose uptake and insulin-stimulated glucose metabolism ${ }^{(8,50)}$.
High-Na diets have been shown to increase the production of leptin in rats ${ }^{(50)}$, which is an important indicator of adiposity ${ }^{(51)}$, and a high-Na diet has been associated with elevated leptin concentrations in humans ${ }^{(52)}$. In previous cross-sectional studies, high $\mathrm{Na}$ intake was associated with body size and fatness ${ }^{(11-13)}$, which play an important role in the pathogenesis of NAFLD ${ }^{(3)}$. In our analysis, we found a positive association between $\mathrm{Na}$ intake and $\mathrm{BMI}$ or $\mathrm{BF} \%$. When we additionally adjusted for $\mathrm{BMI}$ or $\mathrm{BF} \%$ in our multivariable-adjusted model, the association was considerably attenuated. Our results, together with the previous studies described above, suggested that adiposity may partially mediate the association between $\mathrm{Na}$ intake and NAFLD. Another possible explanation might involve abnormal metabolic components. $\mathrm{Na}$ intake is related to abnormal metabolic components including insulin resistance and increased BP, all of which are important factors for the development of NAFLD ${ }^{(3)}$. In our study, however, the estimates did not appreciably change after further adjustment for systolic BP or HOMA-IR. Further investigation is needed to determine whether $\mathrm{Na}$ intake increases risk of NAFLD through other biological pathways or could have some direct effects.

When we stratified the analysis by indicators of adiposity, we consistently found a positive association between $\mathrm{Na}$ intake and prevalence of NAFLD in individuals having low or high body fat (BMI $\geq 23 \mathrm{~kg} / \mathrm{m}^{2}$ or $\mathrm{BF} \% \geq 23 \%$ in men and $\geq 35 \%$ in women), with a slightly stronger association in those with low body fat. We speculated that it might be due to misclassification, partly explained by a tendency for under-reporting dietary intakes among obese individuals ${ }^{(53,54)}$. We also cannot rule out the possibility that this observation could be driven by high statistical power in those with low body fat or could be reflected by chance. Additional studies are needed to elucidate this association.

In our study, we found a slightly stronger association between $\mathrm{Na}$ intake and NAFLD prevalence in women than in men. 
Although the mechanism behind this sex-related difference is unclear, several possible explanations exist. First, BP changes in response to $\mathrm{Na}$ intake were greater in women than in men in a large intervention study ${ }^{(55)}$. Second, physiological studies have suggested that oestrogen and progesterone have important effects in regulating body fluids and $\mathrm{Na}$ content, which are involved in BP regulation ${ }^{(56,57)}$. Third, in a previous observational study, a high prevalence of obesity associated with high $\mathrm{Na}$ intake was more pronounced in women than men ${ }^{(12)}$. These evidences may suggest a sex difference in response to $\mathrm{Na}$ exposure. Further research is needed to reveal the potential sex difference underlying this association.

The strengths of our study include a large sample size and the availability of a wide range of variables related to NAFLD, including comprehensive laboratory and health examination data, which were collected with extensive quality control management and standardisation. However, our study has several limitations. First, given the nature of cross-sectional data, this study cannot directly prove a causal relationship. Second, we cannot rule out the presence of residual or unmeasured confounding factors, although we carefully adjusted for various potential confounders. Third, 24-h urine collection is commonly considered the 'gold standard' tool for measuring $\mathrm{Na}$ and $\mathrm{K}$ intake with complete collection ${ }^{(58)}$. However, collecting 24-h urine samples was not feasible in our clinical setting because of participant burden and cost. Several issues have been raised regarding 24-h urine collection, including the low response rate and collection in representative population surveys ${ }^{(58)}$. The FFQ is designed to reflect long-term dietary intake mostly over the previous year, while a single 24 -urine collection is likely to reflect a short-term period ${ }^{(58)}$, which might have some limitations when examining risk factors for the development of chronic diseases. Although the FFQ is a common method of dietary assessment in observational studies, the FFQ tends to underestimate dietary $\mathrm{Na}$ intake, probably due to under-reporting or difficulty in quantifying the absolute $\mathrm{Na}$ concentration in recipes and capturing the amount of seasoning or sauces added to food during cooking or at the table. However, in the current study, a positive association between salt eating habit score and $\mathrm{Na}$ intake estimated by the FFQ suggested that the FFQ enabled us to rank individuals according to $\mathrm{Na}$ intake levels. In addition, when we analysed foods that are major sources of $\mathrm{Na}$ in our data, including kimchi and ramen, which are also top contributing foods to Korean's Na consumption ${ }^{(49)}$, we found a positive relationship with the prevalence of NAFLD. Fourth, liver biopsy is commonly considered the 'gold standard' for staging NAFLD. Operator dependency, subjective evaluation and restrictions in the ability to quantify the amount of fatty infiltration are potential limitations of the ultrasonography test ${ }^{(33)}$. However, a meta-analysis of thirty-four studies has suggested that ultrasonography can be an accurate and reliable imaging technique for the detection of moderate-to-severe fatty liver in clinical settings and population studies, showing a pooled sensitivity and specificity of 84.8 and $93.6 \%$, respectively, when compared with histology ${ }^{(33)}$. In addition, we found consistent associations when we examined the association with FLI, a surrogate marker of NAFLD. Finally, we excluded participants who did not have reasonable dietary information. Although the study population included in this analysis may not be a random sample of the entire population, ensuring high internal validity was one of the top priorities of our research.

In conclusion, we found that higher $\mathrm{Na}$ intake is associated with a greater prevalence of NAFLD, a relationship that might be partly mediated through adiposity. Our findings provide further rationale for limiting excessive $\mathrm{Na}$ intake and suggest the need for further studies to confirm these findings and to identify the potential underlying biological mechanisms.

\section{Acknowledgements}

This research received no specific grant from any funding agency or from commercial or not-for-profit sectors.

Study concept and design: Y. Choi, J. E. L., S. R.; acquisition of data: Y. Choi, Y. Chang, E. S., H. S., S. R.; analysis and interpretation of data: Y. Choi, J. E. L., Y. Chang, M. K. K., E. S., H. S., S. R.; drafting of the manuscript: Y. Choi, J. E. L., S. R.; critical revision of the article for important intellectual content: Y. Choi, J. E. L., Y. Chang, M. K. K., E. S., H. S., S. R.; statistical analysis: Y. Choi, S. R.; administrative, technical or material support: Y. Choi, Y. Chang, E. S., H. S., S. R.; and study supervision: J. E. L., S. R.

The authors declare that there are no conflicts of interest.

\section{Supplementary materials}

For supplementary material/s referred to in this article, please visit http://dx.doi.org/doi:10.1017/S0007114516003391

\section{References}

1. Neuschwander-Tetri BA \& Caldwell SH (2003) Nonalcoholic steatohepatitis: summary of an AASLD Single Topic Conference. Hepatology 37, 1202-1219.

2. Caldwell SH \& Crespo DM (2004) The spectrum expanded: cryptogenic cirrhosis and the natural history of non-alcoholic fatty liver disease. $J$ Hepatol 40, 578-584.

3. Rinella ME (2015) Nonalcoholic fatty liver disease: a systematic review. JAMA 313, 2263-2273.

4. World Health Organization (2012) WHO. Guideline: Sodium Intake for Adults and Children. Geneva: WHO.

5. World Health Organization (2012) WHO. Guideline: Potassium Intake for Adults and Children. Geneva: WHO.

6. Ogihara T, Asano T, Ando K, et al. (2001) Insulin resistance with enhanced insulin signaling in high-salt diet-fed rats. Diabetes 50, 573-583.

7. Ogihara T, Asano T, Ando K, et al. (2002) High-salt diet enhances insulin signaling and induces insulin resistance in Dahl salt-sensitive rats. Hypertension 40, 83-89.

8. Fonseca-Alaniz MH, Takada J, Andreotti S, et al. (2008) High sodium intake enhances insulin-stimulated glucose uptake in rat epididymal adipose tissue. Obesity (Silver Spring) 16, 1186-1192.

9. Donovan DS, Solomon CG, Seely EW, et al. (1993) Effect of sodium intake on insulin sensitivity. Am J Physiol 264, E730-E734.

10. Hu G, Jousilahti P, Peltonen M, et al. (2005) Urinary sodium and potassium excretion and the risk of type 2 diabetes: a prospective study in Finland. Diabetologia 48, 1477-1483.

11. Song HJ, Cho YG \& Lee HJ (2013) Dietary sodium intake and prevalence of overweight in adults. Metabolism 62, 703-708.

12. Yi SS \& Kansagra SM (2014) Associations of sodium intake with obesity, body mass index, waist circumference, and weight. Am J Prev Med 46, e53-e55. 
13. Yi SS, Firestone MJ \& Beasley JM (2015) Independent associations of sodium intake with measures of body size and predictive body fatness. Obesity (Silver Spring) 23, 20-23.

14. Chatterjee R, Colangelo LA, Yeh HC, et al. (2012) Potassium intake and risk of incident type 2 diabetes mellitus: the coronary artery risk development in young adults (CARDIA) study. Diabetologia 55, 1295-1303.

15. Colditz GA, Manson JE, Stampfer MJ, et al. (1992) Diet and risk of clinical diabetes in women. Am J Clin Nutr 55, 1018-1023.

16. Chatterjee R, Yeh HC, Shafi T, et al. (2010) Serum and dietary potassium and risk of incident type 2 diabetes mellitus: the Atherosclerosis Risk in Communities (ARIC) study. Arch Intern Med 170, 1745-1751.

17. Lee H, Lee J, Hwang SS, et al. (2013) Potassium intake and the prevalence of metabolic syndrome: the Korean National Health and Nutrition Examination Survey 2008-2010. PLOS ONE 8, e 55106.

18. Chatterjee R, Biggs ML, de Boer IH, et al. (2015) Potassium and glucose measures in older adults: the Cardiovascular Health Study. J Gerontol A Biol Sci Med Sci 70, 255-261.

19. Kim CW, Yun KE, Jung HS, et al. (2013) Sleep duration and quality in relation to non-alcoholic fatty liver disease in middle-aged workers and their spouses. $J$ Hepatol 59, 351-357.

20. Ryu S, Chang Y, Choi Y, et al. (2015) Age at menarche and non-alcoholic fatty liver disease. J Hepatol 62, 1164-1170.

21. Chalasani N, Younossi Z, Lavine JE, et al. (2012) The diagnosis and management of non-alcoholic fatty liver disease: practice Guideline by the American Association for the Study of Liver Diseases, American College of Gastroenterology, and the American Gastroenterological Association. Hepatology 55 2005-2023.

22. Ahn Y, Kwon E, Shim JE, et al. (2007) Validation and reproducibility of food frequency questionnaire for Korean genome epidemiologic study. Eur J Clin Nutr 61, 1435-1441.

23. Kim HJ, Paik HY, Lee SY, et al. (2007) Salt usage behaviors are related to urinary sodium excretion in normotensive Korean adults. Asia Pac J Clin Nutr 16, 122-128.

24. The Korean Nutrition Society (2000) Food composition table. In Recommended Dietary Allowances for Koreans, 7th ed. Seoul: KNS.

25. Willett WC, Howe GR \& Kushi LH (1997) Adjustment for total energy intake in epidemiologic studies. Am J Clin Nutr $\mathbf{6 5}$, 1220S-1228S ; discussion 1229S-1231S

26. Mathiesen UL, Franzen LE, Aselius H, et al. (2002) Increased liver echogenicity at ultrasound examination reflects degree of steatosis but not of fibrosis in asymptomatic patients with mild/moderate abnormalities of liver transaminases. Dig Liver Dis 34, 516-522.

27. Oh JY, Kim BS \& Kang JH (2007) Validity and reliability of Korean Version of International Physical Activity Questionnaire (IPAQ) Short Form. Korean J Fam Med 28, 532-541.

28. Chang Y, Kim BK, Yun KE, et al. (2014) Metabolically-healthy obesity and coronary artery calcification. J Am Coll Cardiol 63, 2679-2686.

29. Barros AJ \& Hirakata VN (2003) Alternatives for logistic regression in cross-sectional studies: an empirical comparison of models that directly estimate the prevalence ratio. $B M C$ Med Res Methodol 3, 21.

30. Behrens T, Taeger D, Wellmann J, et al. (2004) Different methods to calculate effect estimates in cross-sectional studies. A comparison between prevalence odds ratio and prevalence ratio. Methods Inf Med 43, 505-509.

31. Zou G (2004) A modified poisson regression approach to prospective studies with binary data. Am J Epidemiol 159 702-706.
32. Adrogue HJ \& Madias NE (2007) Sodium and potassium in the pathogenesis of hypertension. $N$ Engl J Med 356, 1966-1978.

33. Hernaez R, Lazo M, Bonekamp S, et al. (2011) Diagnostic accuracy and reliability of ultrasonography for the detection of fatty liver: a meta-analysis. Hepatology 54, 1082-1090.

34. Bedogni G, Bellentani S, Miglioli L, et al. (2006) The Fatty Liver Index: a simple and accurate predictor of hepatic steatosis in the general population. BMC Gastroenterol 6, 33 .

35. Chang CJ, Wu CH, Chang CS, et al. (2003) Low body mass index but high percent body fat in Taiwanese subjects: implications of obesity cutoffs. Int J Obes Relat Metab Disord 27, 253-259.

36. Huh JH, Lee KJ, Lim JS, et al. (2015) High dietary sodium intake assessed by estimated 24-h urinary sodium excretion is associated with nafld and hepatic fibrosis. PLOS ONE $\mathbf{1 0}$, e0143222.

37. Ryu S, Chang Y, Jung HS, et al. (2015) Relationship of sitting time and physical activity with non-alcoholic fatty liver disease. J Hepatol 63, 1229-1237.

38. He FJ, Li J \& Macgregor GA (2013) Effect of longer term modest salt reduction on blood pressure: cochrane systematic review and meta-analysis of randomised trials. BMJ 346, f1325.

39. Strazzullo P, D'Elia L, Kandala NB, et al. (2009) Salt intake, stroke, and cardiovascular disease: meta-analysis of prospective studies. BMJ 339, b4567.

40. World Health Organization (2003) Diet, Nutrition and the Prevention of Chronic Diseases, Joint WHO/FAO Expert Consultation. WHO Technical Report Series no. 916. Geneva: WHO.

41. The United States Department of Agriculture (2010) Dietary Guidelines for Americans. Washington: Department of Agriculture, Department of Health and Human Services, US Government Printing Office.

42. Mente A, O'Donnell MJ, Rangarajan S, et al. (2014) Association of urinary sodium and potassium excretion with blood pressure. $N$ Engl J Med 371, 601-611.

43. Du S, Batis C, Wang $\mathrm{H}$, et al. (2014) Understanding the patterns and trends of sodium intake, potassium intake, and sodium to potassium ratio and their effect on hypertension in China. Am J Clin Nutr 99, 334-343.

44. Umesawa M, Iso H, Date C, et al. (2008) Relations between dietary sodium and potassium intakes and mortality from cardiovascular disease: the Japan Collaborative Cohort Study for Evaluation of Cancer Risks. Am J Clin Nutr 88, 195-202.

45. Geleijnse JM, Witteman JC, Stijnen T, et al. (2007) Sodium and potassium intake and risk of cardiovascular events and all-cause mortality: the Rotterdam Study. Eur J Epidemiol 22, $763-770$

46. Yang Q, Liu T, Kuklina EV, et al. (2011) Sodium and potassium intake and mortality among US adults: prospective data from the Third National Health and Nutrition Examination Survey. Arch Intern Med 171, 1183-1191.

47. Cook NR, Obarzanek E, Cutler JA, et al. (2009) Joint effects of sodium and potassium intake on subsequent cardiovascular disease: the Trials of Hypertension Prevention follow-up study. Arch Intern Med 169, 32-40.

48. D'Elia L, Barba G, Cappuccio FP, et al. (2011) Potassium intake, stroke, and cardiovascular disease a meta-analysis of prospective studies. J Am Coll Cardiol 57, 1210-1219.

49. Ministry of Health and Welfare \& Korea Centers for Disease Control and Prevention (2014) Korea Health Statistics 2013: Korea National Health and Nutrition Examination Survey (KNHANES VI-1). Cheongju: KCDC. 
50. Fonseca-Alaniz MH, Brito LC, Borges-Silva CN, et al. (2007) High dietary sodium intake increases white adipose tissue mass and plasma leptin in rats. Obesity (Silver Spring) 15, 2200-2208.

51. Kaplan LM (1998) Leptin, obesity, and liver disease. Gastroenterology 115, 997-1001.

52. Zhu H, Pollock NK, Kotak I, et al. (2014) Dietary sodium, adiposity, and inflammation in healthy adolescents. Pediatrics 133, e635-e642.

53. Braam LA, Ocke MC, Bueno-de-Mesquita HB, et al. (1998) Determinants of obesity-related underreporting of energy intake. Am J Epidemiol 147, 1081-1086.
54. Heitmann BL \& Lissner L (1995) Dietary underreporting by obese individuals - is it specific or non-specific? BMJ $\mathbf{3 1 1}$, 986-989.

55. He J, Gu D, Chen J, et al. (2009) Gender difference in blood pressure responses to dietary sodium intervention in the GenSalt study. J Hypertens 27, 48-54.

56. Stachenfeld NS (2008) Sex hormone effects on body fluid regulation. Exerc Sport Sci Rev 36, 152-159.

57. Reckelhoff JF (2001) Gender differences in the regulation of blood pressure. Hypertension 37, 1199-1208.

58. McLean RM (2014) Measuring population sodium intake: a review of methods. Nutrients $\mathbf{6}, 4651-4662$. 